\title{
Sensory aroma from Maillard reaction of individual and combinations of amino acids with glucose in acidic conditions
}

\begin{abstract}
The aroma produced in glucose-amino acids (individual and in combination) Maillard reaction, under acidic conditions at $100{ }^{\circ} \mathrm{C}$ were determined and compared by trained panellist. Proline produced pleasant, flowery and fragrant aroma. Phenylalanine and tyrosine produced dried roses aroma. Alanine produced fruity and flowery odour, while aspartic acid and serine both produced pleasant, fruity aroma. Arginine, produced a pleasant, fruity and sour aroma at $\mathrm{pH} 5.2$, but not at its natural $\mathrm{pH}$. Glycine, lysine, threonine and valine produced a pleasant caramel-like odour. Isoleucine and leucine gave off a burnt caramel aroma. Methionine developed a fried potato odour. Cysteine and methionine produced savoury, meaty and soy sauce-like flavours. A combination of these amino acids produced different types of aroma, with the stronger note dominating the odour of the mixture. This study will help the prediction of flavour characteristics of hydrolysates from different protein sources.
\end{abstract}

Keyword: Amino acids, aroma, Maillard reaction, glucose 